Homero Castillo

\title{
Benavente e Hispanoamérica
}

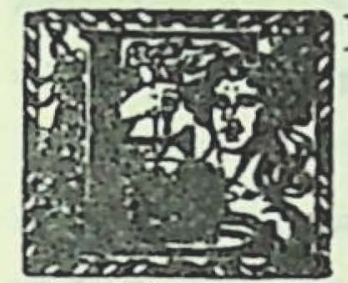

L interés constante por América y los americanos que demostraron los intelectuales del 98 y en especial los integrantes de esa llamada "generación", constituye un tema digno de ser estudiado con detenimiento y minuciosidad, ya que se nos presenta vasto en extensión y atrayente por las modalidades que reviste su tratamiento en manos de los diversos escritores de la época.

El trabajo de Gonzalo Torrente Ballester (1), no obstante su esquemática brevedad, ha significado el principal esfuerzo de conjunto por abrir una brecha que con seguridad, es de esperarlo, orientará hacia investigaciones más detalladamente objetivas, llevará a análisis críticos más pormenorizados y suministrará conclusiones más sólidas y definitivas sobre el tema de la España del 98 y su visión de la América Hispana.

Aunque no se le sugiera en el estudio de Torrente Ballester, hoy no cabe la menor duda de que entre los autores que alternaban en las tertulias del 98 e influían en la cristalización de su fisonomía espiritual, figuraba con asiduidad el dramaturgo Jacinto Benaven-

(1) Gonzalo Torrente Ballester, La generación del 98 e Hispanoamérica, Arbor, tomo XI, N.o 36, Madrid, diciembre de 1948. 
te (2), quien en la última década del siglo pasado había logrado iniciarse y afirmarse en los escenarios de la época con obras que la crítica actual (3), considera representativas (4) de su producción teatral y reflejo bastante fiel del pensar y sentir del 98 (5).

Sin detenerse a considerar que ya por esos años finiseculares Benavente se deleita frecuentemente con los temas americanos, y no obstante la insistente repetición de que los protagonistas de La comida de las fieras provenían de América, Torrente Ballester ni siquiera alude de pasada a tan bien definidos como permanentes intereses del dramaturgo. Por el contrario, el crítico español prefiere centrar su estudio en la producción de Darío, el cual no era hombre del 98, Valle Inclán, Unamuno y Maetzu, refiriéndose muy someramente a otros escritores en cuyas obras de vez en cuando se vislumbra el perfil del continente americano o el de los habitantes que lo pueblan.

En el presente trabajo, al examinar algunas recurrencias y modalidades del tema hispanoamericano tal como se da en las comedias de Benavente, no quisiéramos abarcar la abultada obra del autor.

(2) Ramón Gómez de la Serna, Don Ramón María del Valle Inclán, Buenos Aires, Espasa-Calpe, S. A., 1944; Ricardo Baroja, Gente del 98, Barcelona, Editorial Juventud, 1952; Azorín, Clásicos y modernos, Buenos Aires, Editorial Losada, s. f.

(3) Walter Starkie, Jacinto Benavente, London, Oxford University Press, 1924; Angel Lázaro, Jacinto Benavente. De su vida y de su obra, París, Agencia Mundial de Librería, 1925; Ismael Sánchez Estevan, Jacinto Benavente y su teatro, Barcelona, Ediciones Ariel, 1954.

(4) Hasta el año de 1898, según lo indican con excelente documentación los críticos de nuestras dos notas anteriores, Jacinto Benavente había estrenado con éxito las siguientes obras.

El nido ajeno, en el Teatro de la Comedia, el 6 de octubre de 1894;

Gente conocida, en el Teatro de la Comedia, el 21 de octubre de 1896;

El marido de la Téllez, en el Teatro Lara, el 13 de febrero de 1897;

De alivio, en el Teatro de la Comedia, el 27 de febrero de 1897;

La farándula, en el Teatro Lara, el 30 de noviembre de 1897;

La comida de las fieras, en el Teatro de la Comedia, el 7 de noviembre de 1898 , y

Teatro feminista, en el Teatro de la Comedia, el 28 de diciembre de 1898.

(5) Hans Jeschke, La generación del 98 en España. (Ensayo de una determınación de su esencia). Traducción, introducción y notas de Y. Pino Saavedra, Santiago de Chile, Ediciones de la Universidad de Chile, 1946. 
De hacerlo, caeríamos en una deplorable esquematización y restaríamos todo el relieve que se merecen ciertos rasgos temáticos de primer orden. Preferimos limitarnos a las composiciones benaventinas cercanas al primer viaje del dramaturgo a América, 1906, porque en ellas, en primer lugar, Benavente se encuentra más cercano al espíritu noventaiochista, y luego porque no es aventurado conjeturar que las posteriores visitas al nuevo continente y los honores que en él se le dispensaron como autor de renombre, le hicieran cambiar de parecer o le indujeran a suavizar y acaso refrenar algunos conceptos y sentimientos sobre Hispanoamérica y los criollos que, con anterioridad a esas jiras pasaban más pura y espontáneamente a depositarse en sus escenas. Si bien la afirmación que adelantamos podría ser documentada con el acopio de los numerosos escritos de Benavente posteriores a 1908, fecha de Por las nubes, baste indicar que los juicios críticos y la ironía del dramaturgo con respecto a América y los americanos son mucho más moderados, prudentes y oportunos en los años siguientes de la época que nos proponemos analizar ( $\overline{6})$.

Entre los años de 1894 y 1909, las comedias de Jacinto Benavente, siempre que tratan del tema americano o aluden a él, comprenden esencialmente dos asuntos: el continente americano como entidad geográfica distinta de España y los criollos o los peninsulares asociados con el nuevo mundo.

Ya en el primer estreno de Benavente, El nido ajeno, el lector tropieza con un concepto clave del dramaturgo: América es el continente por excelencia en que los españoles pueden hacer fortunas cuantiosas. Manuel vuelve a casa de su hermano en calidad de galán rico después de haber pasado varios años en América amasando un

(6) Las comedias de Jacinto Benavente que hemos empleado en nuestro estudio son las siguientes:

El nido ajeno (1894), Gente conocida (1896), La comida de las fieras (1898), que se encuentran en Obras completas, tomo I, Madrid, Aguilar, 1941; Por las nubes (estrenada en el Teatro del Príncipe Alfonso, el 23 de diciembre de 1908), en Obras completas, tomo II, Madrid Aguilar, 1942. Para las citas ilustrativas que siguen, hemos utilizado los textos de las ediciones que acabamos de consignar en csta nota; por esta razón sólo damos la página en que se hallan. 
caudal nada despreciable. Sin ni siquiera haber tenido la oportunidad de constatar la veracidad de los rumores que corren acerca de tales riquezas, pues Manuel acaba de llegar y casi no ha alternado con sus parientes por sentirse sumamente cansado del viaje, María, su cuñada, y Emilia, amiga de ésta, no tienen otro tema de conversación que el dinero abundante que el visitante ha logrado almacenar en el extranjero:

María.-...Pero Manuel marchó de España tan joven... No esperábamos volverle a ver.

Emilia.-Dicen que ha hecho dinero por esas tierras. Maria.-_Un gran caudal!

(El nido ajeno, página 4).

Esta creencia de Benavente, sea heredáda de lo que pensaban los españoles desde la época de los conquistadores, sea originada como reacción ante la pobreza económica de España a raíz de los desastres que culminaron con el del 98, constituye el cimiento en que descansa la visión conceptual que el dramaturgo posee de la América española. Los peninsulares se dirigen a esas tierras en busca de los caudales que en vano se esfuerzan por acumular en la madre patria y lo hacen con una fe tan ciega y una determinación tan irrevocable que nada ni nadie los detiene. Tal es el caso de Julio en Por las nubes, quien se separa con gran dolor de su familia y llega a romper su noviazgo con la consiguiente pérdida de la amada porque tiene la certeza de que únicamente en Buenos Aires le sonreirá la suerte. Igual modo de reaccionar se observa en Manolo, primo de Julio, el cual no ve otra solución a las estrecheces económicas en que lo ha sumido su dilatada prole que radicarse en esa América tan promisora a que se marcha su pariente. 
Manolo.-... Porque si vieras que a mí también todos los días me dan unas intenciones de emigrar!... Nuestra casa no es casa, nuestra vida no es vida...

\section{(Por las nubes, página 448)}

Don Hilario, el médico de la familia de Julio, ha sido quien ha arreglado el viaje de este último a América y para ello se ha valido de un amigo suyo que, habiéndose radicado en Buenos Aires, ha prosperado hasta hacer gran fortuna (páginas 452 y 453 ).

Este pensamiento de las riquezas que con desmesurada abundancia y rapidez se logran en América es tan obsesionante que Benavente no sólo lo repitió hasta el cansancio en La comida de las fieras, sino que además lo hizo reaparecer en la comedia Por las nubes con una nueva variación de matiz. Se desprende de Por las nubes que no hay otra fuente posible de riquezas que marcharse a América y al mismo tiempo hablar de gente pudiente es imaginar de inmediato que provienen del nuevo mundo. Esta modalidad que venimos indicando se ve bien claramente en un diálogo que sostienen Luisa, hermana de Julio, y Pepe, el cínico amigo de este último:

Luisa.-Es que Pepe pica más alto. Ya sabe él a quien me refiero; el padre trajo mucho dinero de Cuba.

Pepe.-De Filipinas; pero es igual; el caso es que lo trajo.

(Por las nubes, página 414)

Es sintomático que Luisa al equivocarse lo haga mencionando a Cuba en vez de las Filipinas; para ella, con seguridad, aquel país será fatalmente la fuente de toda fortuna ya que es el único nombre que se le viene a la mente cuando ha de indicar el lugar de que proviene la fortuna de esos desconocidos adinerados. Así resulta perfectamente dable concluir que para el autor, por boca de sus personajes, los cuantiosos caudales del nuevo continente se han convertido en 
pensamiento obsesionante. Es bastante notorio que todos los criollos y peninsulares a su regreso de América, no importa cuál sea el país, se distinguen por los bienes materiales de que disponen: los protagonistas de La comida de las fieras, los americanos que figuran o quedan aludidos en Gente conocida (páginas 94 y 125), el héroe de El nido ajeno y los que figuran en calidad de protectores de emigrantes en Por las nubes.

Observamos, aunque sea de pasada, que dos comedias, El nido ajeno y Por las nubes, a pesar de haber sido escritas en los años 1894 y 1909, respectivamente, es decir, a una distancia de trece años, revelan constantes conceptuales bien marcadas en lo que se refiere a lo de las riquezas americanas. Idéntica uniformidad se notará en el pensamiento y en el sentir del autor al tratar más adelante de otros rasgos temáticos hispanoamericanos.

Aparte de brindar la oportunidad de enriquecerse, América constituye la plena realización de una serie de sentidas aspiraciones de la época y de las cuales Benavente se hace eco con tanta frecuencia que llegan momentos en que tiene que sintetizarlas en pasajes tan clásicos y conocidos como aquel de La comida de las fieras:

En América, el hombre significa algo; es una fuerza, una garantía... se lucha, sí, pero con primitiva fiereza; cae uno y puede volver a levantarse; pero en esta sociedad vieja, la posición es todo; el hombre, nada...; vencido una vez, es inútil volver a luchar. Aquí, la riqueza es un fin, no un medio, para realizar grandes empresas. La riqueza es el ocio; allí es la actividad. Por eso allí el dinero da triunfos, y aquí desastres... Pueblos de historia, de tradición; tierras viejas, donde sólo cabe, como en las ciudades sepultadas de la antigüedad, la excavación, no las plantaciones de nueva vegetación y savia vigorosa. 
Esta antítesis de una España sombría y noventaiochista frente a una América que es tierra de promisión en que se concretizan ambiciones diametralmente opuestas a la abulia generacional, constituye otra nota que con frecuencia externa o virtual se manifiesta desde el año 1894 hasta 1909 en el teatro de Benavente. En efecto, en Por las nubes, once años después del estreno de La comida de las fieras, el dramaturgo repite:

Julio.-Esta es la carta... Lee, lee. Un empleo muy lucrativo que me permite iniciativas... Desde luego, mejor retribuído que aquí... y sin la pesadumbre de tener que vivir como un señorito. $\mathrm{Y}$ en él tendré la satisfacción de trabajar en algo útil, provechoso. No sentiré el descorazonamiento que se apodera de mí en nuestras oficinas, despachando expedientes y revolviendo papeles cuya utilidad no se me alcanza siempre, y me hace pensar muchas veces si no serán nuestras oficinas una piadosa fundación de la caridad oficial en favor de esta desvalida clase media, que no puede refugiarse en oiros asilos. Hilario.-Sí, señora; sí... La posición que mi amigo ofrece es excelente para quien vaya dispuesto a trabajar... Ya lo sabe Julio: allí hay que dejarse de ser señorito intelectual, que sólo emplea un intelectualismo en criticar a los que trabajan. Inteligencia, la que basta para ponerla al servicio de una buena voluntad. Voluntad, sobre todo... No como aquí, donde nos pasamos lo mejor de la vida maldiciendo del que construye el edificio que soñamos... que es tan hermoso, tan hermoso, que no llegará a construirse nunca.

Julio.-Pues quiero levantar yo $\mathrm{mi}$ casa nueva... Y sobre tierra nueva, no sobre ruinas.

(Por las nubes, página 470).

Idéntico destino le habría aguardado a Manuel, dice María en El nido ajeno, si hubiera permanecido en esa España desolada física y espiritualmente: 
Los impulsos emprendedores de su espíritu se hubieran resuelto en luchas mezquinas... en calaveradas indignas de su ánimo generoso... En medio a propósito (América) donde explayar su genio, ha sabido educarse por la conciencia propia, que es la mejor educadora cuando el corazón está sano.

\section{(El nido ajeno, página 24 ).}

El continente americano, no obstante ser fuente de riquezas y constituir la tierra del futuro en que el individuo ha de saciar la sed material y espiritual que en su patria no consigue ni siquiera en sueños, se transforma para el españoi peninsular ya ubicado en su nuevo medio en un lugar extraño en que no se siente completamente a gusto. Manuel, en El nido ajeno, insiste una y otra vez en aquello de verse extranjero en América:

$¡$ ¡Ansioso vengo de cariño! ¡He vivido tanto tiempo solo!... Extraño en todas partes. Mi protector, mi verdadero padre, don Gabriel, murió a poco de llevarme consigo. Desde entonces no he tenido un amigo, no he tenido a nadie. Ni aventuras pasajeras, ilusiones de amor, para engañar mi soledad tristísima.

$$
\text { (El nido ajeno, página 15). }
$$

Los temores que abrigan los que se oponen al viaje de Julio a Buenos Aires, en Por las nubes, obedecen seguramente a los mismos sentimientos de separación, soledad y aislamiento de que se queja Manuel en El nido ajeno, y de los cuales Julio bien pudiera ser víctima al alejarse del hogar. Es que el dramaturgo es quien abriga la sospecha de que América todavía representa una incógnita social que, a pesar de estar repleta de sorpresas alentadoras y estimulantes, puede a la vez tornarse en factor deprimente al acrecentar la nostalgia por los seres queridos de quienes los protagonistas se han separado con tanto pesar. Es así como se agudiza y agiganta 
la angustia de los aventureros benaventinos alejados y aislados en ambientes extraños. Cuando en la obra de Benavente llega a prevalecer este modo de enfocar al continente americano, Europa muda su faz y renace con todos los encantos que el español no halla y echa de menos en el nuevo mundo. Tal es el sentir que revela Manuel, en $E l$ nido ajeno, cuando después de quejarse con repetida e infantil insistencia de la soledad en que se encontraba sumido en América, hace planes con su cuñada para emprender un viaje de recreo:

Por tierras alegres de cielo azul y sol de fuego, de flores y cantares... Por Andalucía, por Italia... Sevilla, Málaga, Venecia, Nápoles..., donde amanece el día con más luz y el vivir por sí solo es alegría; donde los pobres cantan y el viento susurra y los mares mecen... ¡Tierras que Dios bendice!... ¡Donde ni el pecar es pecado!

(El nido ajeno, página 38).

Peregrina ceguera es la de Manuel e inexplicable su incapacidad para apreciar durante su estancia en América todo aquello que ve en una Europa idealizada a base de lugares comunes que con seguridad jamás ha visto en su aciaga infancia y juventud. Todo ello, sin duda, se debe al desconocimiento completo que por entonces poseía Benavente de los encantos naturales de las tierras del nuevo mundo y de la calurosa recepción que los americanos brindan a los extranjeros. Benavente nunca reveló en sus obras ninguna sensibilidad para apreciar el ambiente americano que ha dado origen a una excelente literatura en manos de autores de mayor aptitud para captar el sentido estéticamente distintivo de un paisaje o de un medio, ni demostró su reconocimiento por la calurosa acogida, los innumerables festejos y los señalados honores que repetidamente se le brindaron en las dos Américas. Si bien el tono satírico es menos enconado y la ironía menos hiriente en las obras posteriores a 1925, su entu- 
siasmo por América nunca se cristalizó en nada parecido a los renglones de la última cita nuestra. A lo más América es un excelente sueño que hace olvidar la postración del 98 con la esperanza muy placentera, por añadidura, que nos ofrezca una mina o un pozo de riquezas.

En las obras de Benavente el lector pronto se familiariza también con una abigarrada galería de criollos y peninsulares, cuyas personalidades oscilan desde la ridícula extravagancia de los nuevos ricos hasta la más ejemplar cordura y sensatez que es dable imaginar en un mortal. Si quisiéramos clasificar a los criollos con el fin de caracterizarlos, sería preciso distinguir entre los que están radicados en América y a los cuales Benavente sólo puede imaginarse, y los acaudalados que habiendo abandonado su país de origen sientan sus reales en Europa o en España. No parece prematuro adelantar a estas alturas que los primeros están concebidos y trazados a base del conocimiento que el dramaturgo pudo tener de los segundos o de datos que recogió en charlas de sobremesa, ya que a América ni había soñado dirigirse por aquellos años.

Los criollos que residen en sus respectivas tierras son ocasionalmente presentados como seres un tanto desvalidos, dignos de piedad e incapaces de valerse por sí mismos:

Manuel.-¡Soy bueno! ¿No es verdad?... Lo dices tú, mi madre lo decía también, las dos personas mejores que he conocido. ¡Tendré que creerlo!...

María.-Lo dicen muchos pobres también, Manuel. Todo se sabe.

Manuel.-Eso no. ¡Vaya un mérito dar lo que a uno le sobra!

María.-Es que en América bendicen tu nombre muchos desvalidos; es que hiciste la caridad con amor.

(El nido ajeno, página 14). 
En términos generales, el criollo que vive en América a menudo se destaca como un tipo extravagante, antojadizo y pedante hasta el extremo de hacerse o sumamente antipático o socialmente inaceptable:

Teles.-Oye, ¿no decías que la de Alsina era americana?

Tomillares.-No; es española. Se casó en París con un americano riquísimo que luego fué presidente de no sé qué República de esas fantásticas de América.

Teófilo.- ¡Oh, graciosísimo! Sarah Bernhardt me contó en una ocasión que trabajando ella en un teatro de no sé qué República americana, durante el primer entreacto entró el presidente a saludarla; al segundo entreacto vuelve a entrar, y era otro presidente: durante el acto había habido una revolución...

(La comida de las fieras, página 310 ).

No cabe duda que las ingeniosas ocurrencias críticas que salpican de ironía las ideas que Benavente poseía de los criollos en su patria y de los peninsulares avecindados en tierras americanas o vueltos a España en calidad de nuevos ricos se hallan integradas y cuidadosamente trabajadas en La comida de las fieras, pero los gérmenes de estas personalidades se encuentran bosquejados con rasgos algo caricaturescos en obras suyas anteriores a 1898:

Anstirez.-. De esos ricachos de Cuba que de cuando en cuando vienen a asustarnos con su dinero y al año suelen volverse a su tierra como pintan a sus ascendientes antes de que los descubriera Colón, es decir, peor porque aquéllos los pintan con plumas, y éstos suelen quedarse desplumados.

Pilar.- ¿Son muy ricas?

San Severino.-Así parecen. Sobre todo son elegantes. Por eso se las admite en todas partes. No hay en Madrid quien vista como ellas. 
Ansúrez._-iVamos! Se han propuesto hacer papel como se hace el papel; después de todo, a fuerza de trapos.

(Gente conocida, página 94).

Pưliendo oon metódica perseverancia estas agudezas algo estridentes de Gente conocida y ampliando la acción para darle la debida longitud, variedad, forma, proporción y número de alternativas episódicas, Benavente entregó al público la celebrada comedia intitulada La comida de las fieras, en que el asunto en sus líneas generales no es nada nuevo, pero el tratamiento del mismo y el tema que se sugiere son de una maestría digna de elogio.

Los Alsina "esos americanos que tanto ruido hacen ahora en Madrid", gastan un capital atendiendo a las aristocráticas amistades que los rodean. Victoria Alsina es guapa, viste bien, ha puesto casa con verdadero gusto artístico, pero tiene el grave defecto de ser "una niña caprichosa que se divierte con rarezas". Su extravagancia llega hasta el extremo de ocasionar un verdadero incendio para así dar más realidad a una absurda representación modernista que tiene lugar en su mansión señorial:

Victoria.-La verdad es que si no tenemos agua cerca... ¡Se ha hecho un boquete en la alfombra!... La lástima es que no hemos visto concluir la comedia!... Hay que repetirla otro día...

Tomillares.-Ha sido una nota modernista. ¡Otro símbolo! Teófilo.- ¡Oh, sí! ¡En medio de todo, era delicioso! El teatrillo entre llamas y dos jóvenes lindísimas volcando un tibor lleno de rosas sobre el fuego... y el agua y las flores cayendo sobre las llamas... ¡ Un verdadero cuadro prerrafaélico!

(La comida de las fieras, página 321). 
Junto a la figura de esta española contagiada de americanismo, se encuentra la de su esposo, Hipólito Alsina, quien, por su parte, tiene "asustado a Madrid... desconcierta a los hombres de negocios con jugadas de Bolsa atrevidísimas”, las cuales, según el astuto Fermín, no son más que disparates porque el acaudalado forastero "se empeña en sostener un alza artificial, contra el sentido común” y "a ese paso no hay capital que resista" (7).

Los esposos Alsina, aunque mirados con recelo y envidia por los madrileños siempre dispuestos a adular a los ricos, merecen desde el primer momento elogiosos comentarios por su comportamiento moral ya que no sólo es él "muy simpático y muy caballero", y ella "encantadora", sino que además son ejemplo de buen entendimiento matrimonial. Esto último, claro está, no les parece de buen tono a ciertos cínicos madrileños que se dedican a esparcir toda suerte de insidiosas murmuraciones sobre el pasado de los Alsina o a provocar desvergonzados comentarios que los dejan en un completo desnudo espiritual:

Teles.- ¿Y se lleva bien el matrimonio?

Marqués.-Están realmente enamorados uno de otro. ¿Verdad, Luis?

Teles.-¡Pero eso es una cursilería!

Marqués.-No, eso era antes. Ahora se lleva mucho la virtud.

Teles.-Eso te lo habrá dicho tu tía.

(La comida de las fieras, página 311).

La ingenuidad desmedida de los Alsina, su generosidad y desprendimiento mezclados con una chocante pedantería y afán de

(7) La falsa impresión de desconcierto que los ricos americanos producen en los círculos madrileños, así como la extravagancia con que los "rastacueros" gastan sus fortunas son tema de las renovadas agudezas con que Benavente se complace en zaherir a los criollos: Cf. Gente conocida, págs. 94,$125 ; \mathrm{La}$ comida de las fieras, págs. 299, 303, 304, 305, 309, 310, 311, 315, 319, 320, 321, 322, 327, 333, 334, 337, 344; Por las nubes, págs. 414, 430, 453. 
deslumbrar, a la vez que la inexperiencia en el trato con el encallecido alto mundo madrileño, todo ello en heterogéneo torbellino los arrastra y hunde en la ruina. Hipólito, con atrevida inocencia, cae víctima de inescrupulosos especuladores que sin remordimiento de ninguna clase los sumen a él y a su esposa en la bancarrota más completa. Sin embargo, en medio de este infierno de falsedades en que se sofocan los Alsina, siempre se vislumbra una nota de sincera generosidad con que el autor ha querido teñir a los protagonistas. Este es el único caso en que Benavente olvida sus obsesionantes ideas sobre las ridiculeces de los criollos para presentarlos como seres más bien cuerdos y generosos que alocados y despilfarradores. Es de observar, no obstante, que esta nueva manera de caracterizar a los americanos es meramente accidental o circunstancial, puesto que en toda la producción restante, Benavente vuelve una y otra vez a repetir su cantinela de la extravagancia, desmedida riqueza e inadaptación social de los americanos. De estas breves consideraciones se desprende que los tintes con que se distingue la caracterización de los Alsina obedecen, no tanto a un cambio de actitud mental del dramaturgo hacia los hispanoamericanos, sino a la necesidad apremiante de atenuar la amarga indolencia con que había saturado el ambiente metropolitano español en los actos iniciales de la comedia. Por eso se le confía a Victoria el secreto de la insolvencia en que temen haber quedado postradas sus amistades. La intercesión de ella ante Hipólito para que éste salve como mejor pueda a los arruinados, marca el momento crucial en que predomina la bondad de los Alsina sobre la ruindad de sus relaciones españolas. Al menos si ésta no desaparece por completo, aquélla la atenúa. En efecto, Victoria, sin comprender la trascendencia de la situación, no titubea ni un momento en comunicar a su marido el grave peligro en que se encuentran sus conocidos. Los esposos, entonces, en una escena ejemplar para el público madrileño, acaso asqueado de tanta pequeñez, comparten los sinsabores de la desgracia y la incomprensión inminentes fundiéndose espiritualmente en una íntima comunión de sentimientos de la más pura generosidad, ternura 
y amor. La longitud de la escena nos obliga a extractar los renglones más significativos para comprender el cambio de tono a que ha recurrido el autor en la caracterización de los personajes que nos interesan:

Victoria.-¿Tú crees que Manuel es un hombre honrado? ...Yo no entiendo mucho de vuestros asuntos; pero si sólo ha pecado de imprudente o de ambicioso...

Hipólito.- $\mathrm{Si}$ no necesitas hablarme en su favor. $\mathrm{Si}$ yo quiero salvarle, no sólo por amistad, sino por interés; porque mi crédito padecería...

Victoria.- ¡Ah! ¿No se trata sólo de él; se trata de ti? ¿Y dudas todavía? ¿Por qué dudas?

Hipólito.--Porque, desgraciadamente, me persigue la mala estrella en los negocios; porque, a pesar mío, he comprometido más de lo que debiera un capital... que no es mío.

Victoria.- ¡Hipólito! ¿Que no es tuyo? ¿Entonces de quien dudas es de mí?. .

Hipólito.- ¡Sí, perdóname! ¡No sé cómo puedo dudar de ti!

Victoria.-Porque pocas veces te hablo de mi cariño, Porque creí que de tal modo lo veías, que no necesitaba explicártelo con palabras.. , no; nunca te he dicho cómo te quería... un amor que es toda mi vida...

Hipólito.- ¿Qué hice yo para merecer tanto cariño?

Victoria.-iAhora es cuando me parece alegre nuestra fiesta! ¡Ahora que has decidido salvar a tu amigo de la miseria, que puedo devolver la tranquilidad a dos pobres mujeres!... ¡Corre!..., dile a Manuel que esta noche mismo...

Hipólito.- - Le diré que se arrodille ante ti, como yo me arrodillo!

(La comida de las fieras, páginas 326 y 327).

Ya en el último acto, cuando la catástrofe se ha consumado, las notas dramáticas que caracterizaban a los personajes persisten sólo 
a manera de ecos prolongados de los hipertonos con que Benavente se había esforzado por deleitar al auditorio en los actos iniciales. Los criados de nuevo comentan las estridencias sociales y las aventuras bursátiles de los Alsina, en tanto que los aristocráticos peninsulares retribuyen la inocente, pero sincera generosidad de los forasteros americanos con despiadadas puñaladas a mansalva. Los Alsina, por su parte, han despertado de su sueño y vuelven a la realidad con firme entereza para enrostrar al cínico e hipócrita Tomillares el doble juego que ha venido haciéndoles. En este altercado se deposita el último residuo de la perversa y solapada maldad de la sociedad madrileña que Benavente inequívocamente ha querido hacer patente en las tablas. Al mismo tiempo la transformación de las respectivas personalidades de los criollos ha llegado a realizarse como lo proyectara el dramaturgo:

Hipólito.-...Han traído y han llevado nuestros nombres... y hemos figurado como unos aventureros trapisondistas. Victoria.-No es la única calumnia que ha caído sobre nosotros.

Tomillares.-Pero nadie...

Hipólito.-Todos aparentan no creerlas, nadie quiere ser responsable de haberlas inventado pero corren de boca en boca por si tropiezan con alguna que las confirme con verdad.

Tomillares.-Si alguien delante de mí...

Hipólito.- ¡ $\mathrm{Si}$ alguien delante de usted nos calumnia, repita usted lo que dijo usted aquí a varias personas, cuando profetizaba usted lo que muy pronto sucedería!...

De las notas hasta aquí apuntadas bien se puede concluir que el concepto predominante de Jacinto Benavente acerca de Hispanoamérica es que constituye un continente de grandes posibilidades materiales y espirituales, un mundo de esperanzas ante la desolación nacional circundante y un antídoto eficaz para el veneno que corroe el espíritu de la época. Los temores que abriga el autor se deben 
principalmente a su desconocimiento de las tierras americanas y de los habitantes que las pueblan, así como a la falta de capacidad de los españoles para adaptarse al medio que los acoge. Benavente mismo en señaladas ocasiones dió muestras de padecer de este mal. Por otra parte, resulta innegable que en el pensamiento del dramaturgo el nuevo mundo se presenta como una fuente inagotable de riquezas que a fuerza de tesón se logrará conquistar para sí porque "no hay nadie allí que no haya sido rico una vez" (La comida de las fieras, página 310).

Los criollos, volubles y caprichosos en su tierra, pedantes hasta la extravagancia en un medio extranjero al que sólo van a empobrecerse, ignoran con lamentable e inocente inexperiencia las malévolas triquiñuelas de la sociedad española en general y de la madrileña en particular. Si los americanos aprenden a conocer la realidad, lo consiguen a fuerza de amargos fracasos, desengaños y sinsabores, como en el caso de los Alsina. Lo más notable en la conducta de éstos es que la adversidad los une y estrecha espiritualmente, los hace despertar y les facilita su adaptación al medio europeo, aunque sea en el momento más aciago de su vida. La caracterización de los Alsina, según lo indicamos, con su doble personalidad, obedece a exigencias escénicas y no a un cambio de parecer del autor, quien con mucha mayor frecuencia se deleitó ridiculizando a sus amigos americanos que presentándolos con la comprensión por él dispensada a los Alsina. En contraste con la cordura de los Alsina para sobrellevar sus penas en El nido ajeno y en Por las nubes, ante el conflicto que ha surgido se produce un divorcio de almas total y catastrófico. Los peninsulares resultan ariscos, malévolos, rebeldes, inadaptados en ambientes extranjeros y en su propia tierra. Por este motivo se sienten aislados, tristes y forasteros en las tierras americanas y quedan ciegos o insensibles ante las riquezas naturales que se les brindan y fríos ante la calurosa y sincera hospitalidad con que los acogen sus habitantes. Al enfocar así a sus conterráneos y a los criollos, Benavente cumple con su disposición muy personal de darnos en las tablas una realidad humana tal y como él la ve. 